\title{
Design and Development of Integrated Stationary Cycling Charger for Promoting Healthy Lifestyle
}

\author{
Z. Rasin, F. Daud, M. A. M. Zan, N.A. Rani, M. A. Yazid
}

Abstract: A powerful smartphone with all the high-end features has becomes one of the basic necessitie in today's modern life. People use the smartphone not only for communication purpose, but for other things such as entertainment, education, and work. As our life has becomes very much dependent on this kind of technological gadget which makes everything easier and faster to access, it becomes a main reason for our lack of daily physical activities which poses potential health issues such as obesity, high cholesterol level and high blood pressure. Despite various brands and models of a smartphone, one thing in common is the use of battery to power the device, where it needs to be recharged over time. The movement of wheel with a motor installed able to generate electricity thus powering the battery. In this research, the enjoyable and healthy activity of cycling is further upgraded to become what is known as a "cycling charger" as a way of promoting a healthy lifestyle within the community. It focuses on the conceptual design and prototype development of a stationary cycling charger which can be located everywhere within the public area for easy access and usability. The specification and parameters of the cycling charger are determined based on the average potential users, including the electrical capacity and device protection. It is then followed by the modelling and simulation works using a software to determine the feasibility before proceeding to the prototyping stage where all the designed circuitries are fabricated and integrated with sensors and microcontrollers for processing information and providing user interface. Lastly, several measurement and operation verification are conducted to ensure a satisfactory operation of the developed cycling charger. It is verified the developed prototype can be operated at a minimum cycling speed a low as $8 \mathrm{~km} / \mathrm{h}$ which is good for wide range of user with different cycling ability. Its size which is basically based on the available stationary cycling exercise platform and together with an independent battery supply for all its operation make it easier and flexible to be installed within the public area.

Revised Manuscript Received on December 30, 2019.

* Correspondence Author

Zulhani Rasin*, Faculty of Electrical Engineering, Universiti Teknikal Malaysia Melaka, Malaysia. Email: zulhani@utem.edu.my

Faiz Daud, Public Health Department, Faculty of Medicine, Universiti Kebangsaan Malaysia, Malaysia. Email: faizdaud@ppukm.ukm.edu.my

Muhammad Amruha Md Zan, MZ Turbo Energy Oil Sdn Bhd, Malaysia. Email: xambrox@gmail.com

Natrah Abd Rani, Public Health Department, Faculty of Medicine, Universiti Kebangsaan Malaysia, Malaysia. Email: natrah_rani@yahoo.com

Mohd Akhmal Syafi Md Yazid, Faculty of Electrical Engineering, Universiti Teknikal Malaysia Melaka, Malaysia. Email: b011720028@student.utem.edu.my

(C) The Authors. Published by Blue Eyes Intelligence Engineering and Sciences Publication (BEIESP). This is an open access article under the CC BY-NC-ND license (http://creativecommons.org/licenses/by-nc-nd/4.0/)
Keywords : stationary cycling charger, DC motor, healthy lifestyle

\section{INTRODUCTION}

The realization of charging an electronic device through cycling activity has been long explored from conceptual design up to the commercialized products. As shown in Figure 1, products such as Pedal-A-Watt [1], Recharge Station[2], WeWatt Kiosk [3] and many more are available, with the concept of integrating the healthy and enjoyable cycling activity with a process of charging an electronics devices such as smartphone and tablet, which already becomes a necessity in most people's daily life.

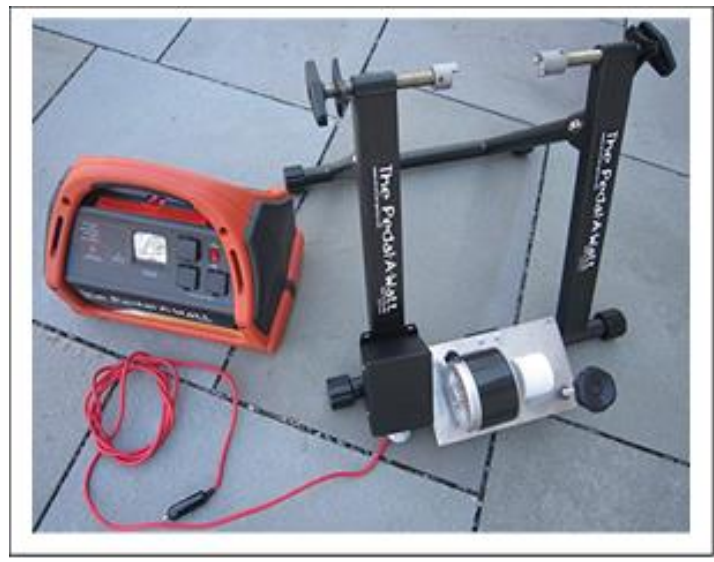

(a)

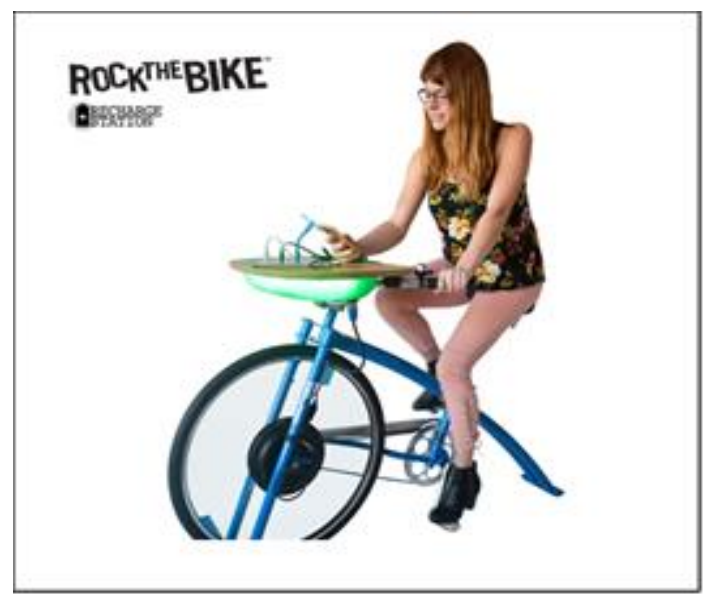

(b) 


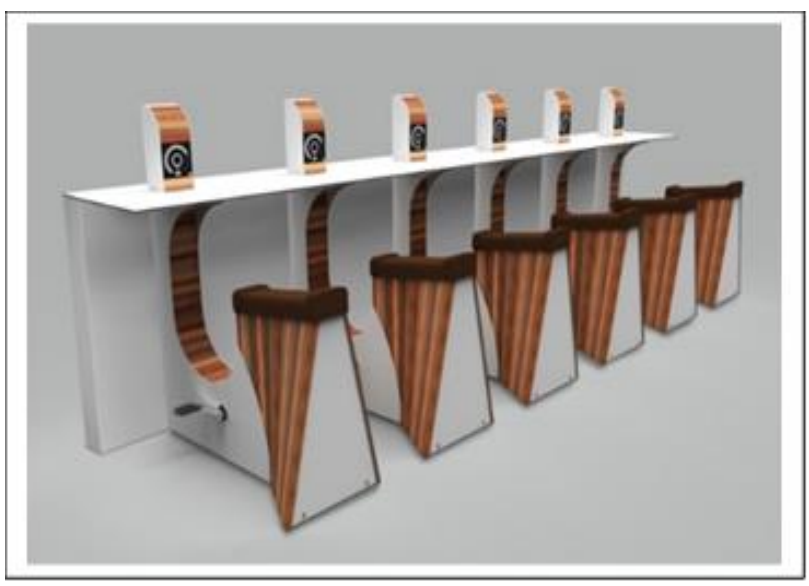

(c)

Fig. 1. Among currently available commercial cycling charger products in the market (a) Recharge Station [1]

(b) Pedal-A-Watt [2] and (c) WeWatt Kiosk [3].

In relation to healthy lifestyle, based on the article by star2.com [4], Malaysia is currently Asia's fattest country with approximately half of the population is overweight or obese. As a result, diseases such as type 2 diabetes, cancer, cardiovascular disease, stroke and chronic diseases are increasing at a worrying level. For that an aggressive strategy is necessary to educate the community about having a more positive and active lifestyle. Here is where the cycling charger can be used as an instrument in promoting and educating people on the importance of exercise and physical activities in their daily life.

There are many battery chargers which have been presented previously in the literature. These include the battery charger designed based on the switching-mode power supply (SMPS) converters such as in [5] - [6], switched-capacitor based chargers and low-dropout (LDO) voltage regulator [7] - [8]. They are all featuring a small chip size and simple structure, ability to operate in dual-mode operation which enables the trickle/large constant-current mode to constant-voltage mode with different charging rates, lower switching losses and higher power density. Among the issues raised are problem on passive elements which are too huge for the space and power efficiency problem.

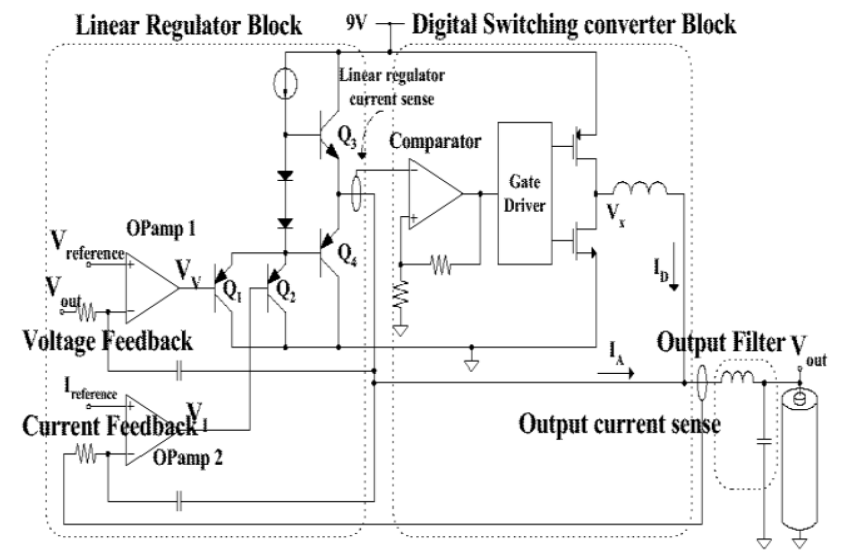

(a)

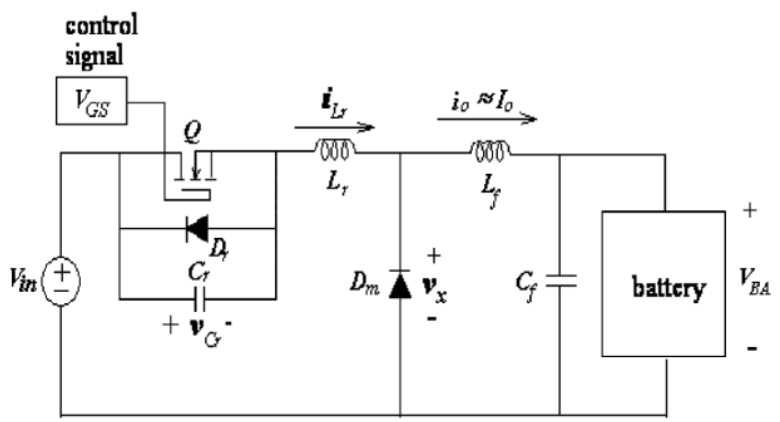

(b)

Fig. 2. Among the proposed battery charger topologies in the literature (a) analogue-digital switching mixed mode battery charger [7] and (b) buck ZVS resonant converter based battery charger [6].

The currently available products in general are applying topologies as shown in Fig. 3 [9] in converting the energy produced by the mechanical rotation of the bicycle wheel to the usable electrical energy for charging the battery of the smartphone or tablet devices. Here the dynamo AC voltage generated based on the rotation of the wheel is firstly rectified by the H-bridge diode and converted into a DC voltage and next the voltage regulation is implemented based on the use of analogue bipolar power transistor or a more advanced switched regulator. LC filter is used for smoothing the output voltage and current as well as the use of zener diode for overvoltage/current protection.

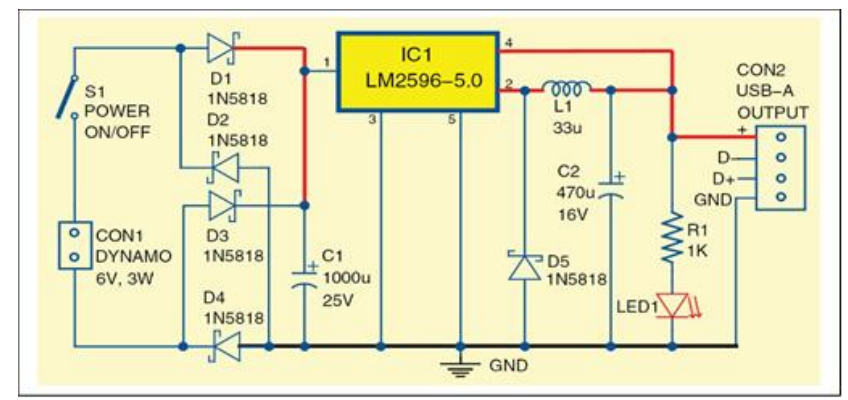

Fig. 3. General topologies of electrical circuit for conversion of mechanical energy to electrical energy for battery charging purpose[9].

This kind of topology however has several drawbacks and area of improvement for the currently available commercial products can be discussed as follow.

Firstly, the rectification stage needs 4 diodes to rectify the AC voltage and ripples are still exist in the produced output voltage and DC link capacitor is necessary to smoothen the DC voltage. By directly using a DC motor as power generator, the use of diode bridge and DC link capacitor can be eliminated. This helps to reduce components and the overall cost.

Secondly, The use of analogue regulator for voltage regulation contributes to less efficiency due to the fact that the transistor operates in its linear region which in effect works as a variable resistor resulting in losses. 
This contributes to inefficiency of the overall system. This can be improved by using the switching DC-DC converter which proven better in term of efficiency and flexible voltage regulation through a closed-loop control.

Thirdly, lithium ion charging characteristics Lithioum-ion battery is widely used as the energy storage for the electronics devices such as smartphone, laptop and tablet. It has a higher voltage per cell, tighter voltage tolerances and the absence of trickle or float charge. For that, voltage regulation during charging process is very importance to prevent overvoltage stress on the battery which could compromise the safety aspect. Unlike the other type of energy storage such as the lead acid battery, it does not need to be fully charged and for that, a simplified "charge-and-run" method which is widely used by the low-cost consumer chargers may not be suitable. By using the switched DC-DC converter, charging voltage can be controlled appropriately especially for realizing the saturation charge stage, and adjustable end-of-charge voltage which helps to prolong the service life of the battery.

Lastly, cycling charger as a tool of promoting/educating healthy lifestyle within the community - Utilizing the cycling charger as a tool to effectively promoting and educating people to exercise means that additional features are necessary to be added to attract people to use it to charge their electronic devices. Other than placing it in the public interest area such as airport, shopping mall, public transportation area etc, the experience will be more enjoyable if the users able to know how much energy they have produce, how much calories have been burned and so on. This can be realized through the used of LED displays and user interface features to obtain the users' biological information.

\section{METHODOLOGY}

\section{A. Conceptual Design of the Stationary Cycling Charger}

Fig. 4 shows the conceptual idea of the final product. It mainly composed of a stationary bicycle frame, DC motor as a power source, electronics circuitries for protection, conversion and regulation of voltage and current, microcontroller unit for data processing and lastly the screen for information display.

\section{CYCLING CHARGER STATION}

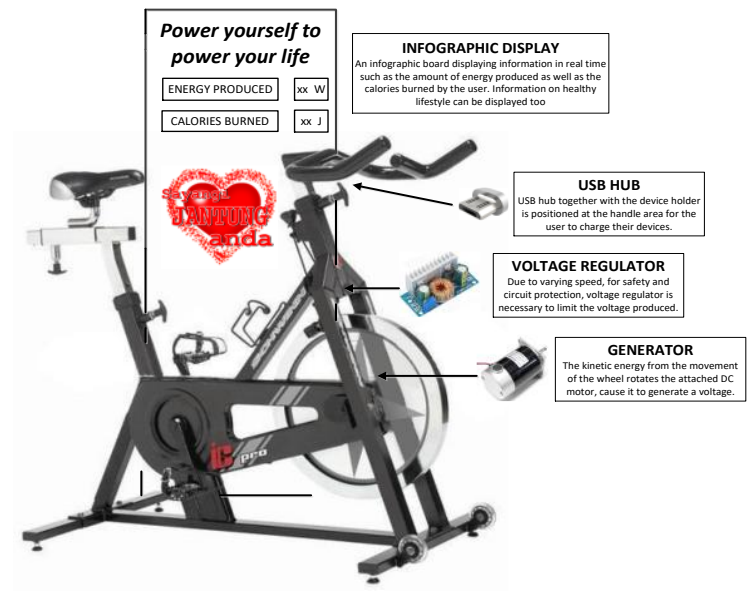

Fig. 4. Conceptual design of the stationary cycling charger.

\section{B. DC Motor as a Power Source}

The cycling movement rotates the shaft of the DC motor and produced the electromotive force (emf) voltage that becomes the main power supply for the charging circuit. The use of DC motor eliminates the rectification stage required in the conventional dynamo based cycling charger. Fig. 5 shows the XYD-6D model 24V 350W 2600 rpm brushed direct-current motor from Electric China used for the prototype. It has 20A current rating and efficiency of more that $75 \%$ with dimension properties fit to the bicycle frame.

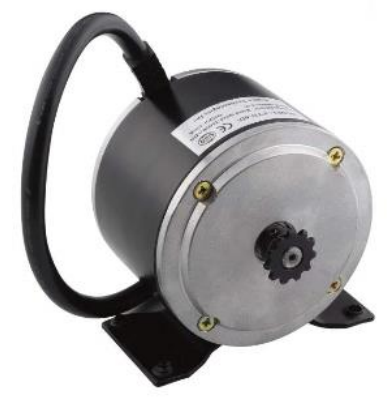

Fig. 5. XYD-6D brushed DC motor from Electric China.

\section{Electronics Circuitries and Systems}

Fig. 6 shows the electronic system for the cycling charger operation. The voltage $V_{\text {in }}$ produced from the rotation of the DC motor is smoothen by input capacitor $C_{i n}$, before being supplied to the DC-DC buck converter based on TPS5450 package from Texas Instrument [10] with functional block diagram shown in Fig. 7. It is designed to accept an input voltage source of 5.5-36 V input voltage and provides up to $5 \mathrm{~A}$ output current. Operating at $500 \mathrm{kHz}$ switching frequency which is internally set, the package includes the MOSFET together with the gate drive circuitry. The output voltage of the DC-DC converter is controlled through implementation of constant-frequency voltage-mode control with voltage feed forward, thus improving the line regulation as well as line transient response. The bootstrap capacitor $C_{1}$ connecting pins BOOT and $\mathrm{PH}$ of the package supplying the gate-drive bias voltage for the integrated high-side MOSFET. The default input start-up voltage is at $5.3 \mathrm{~V}$ which can be achieved with a lower cycling speed. The package also has an overvoltage protection mechanism to mitigate the output voltage transients, where the MOSFET is turned off and remains off until the voltage is less than $112.5 \%$ of the desired output voltage. The internal cycle-by-cycle overcurrent protection limits the peak current by entering the hiccup mode together with the thermal protection to protect the device from overheating.

The Arduino mega 2560 microcontroller board based on ATmega2560 [11] shown in Fig. 8 is used to process the information and signals for the operation of the cycling charger. From the main circuit, voltage, current and proximity sensors detect the input voltage $V_{i n}$, current $I_{\text {in }}$ and speed $\omega$ respectively, relaying the signals to the microcontroller. 


\section{Design and Development of Integrated Stationary Cycling Charger for Promoting Healthy Lifestyle}

The microcontroller also receives the data input by the user through the smart display screen which includes the weight, gender, age and height of the user. Based on all of these data and signals, the screen displays the cycling speed, the cumulated charging power and estimation of amount of calories burned in real time. The display unit used is the 3.5 inch, 480x320 pixel resolution resistive touch screen TFT LCD which has compatibility with the used Arduino microcontroller board as shown in Fig. 9.

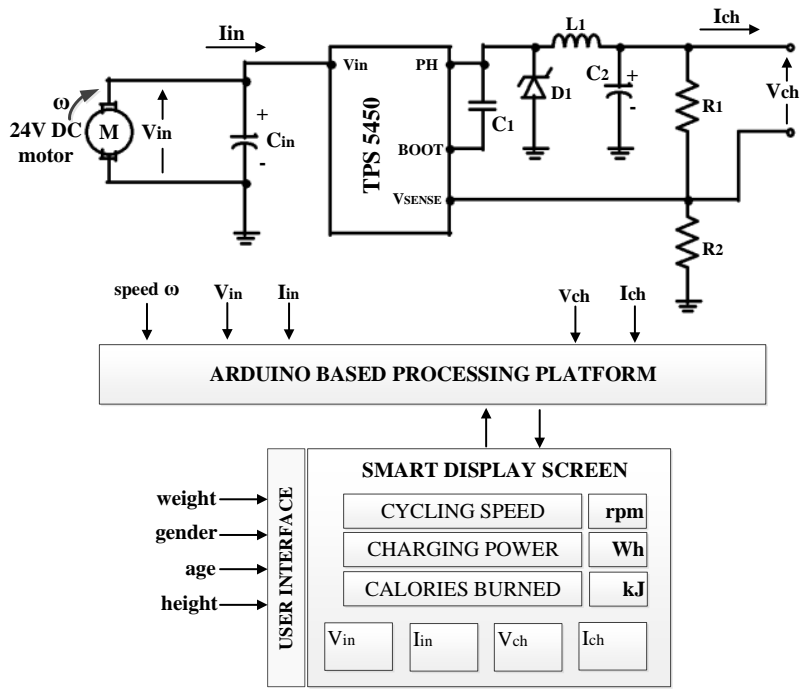

Fig. 6. Electronic system of the cycling charger.

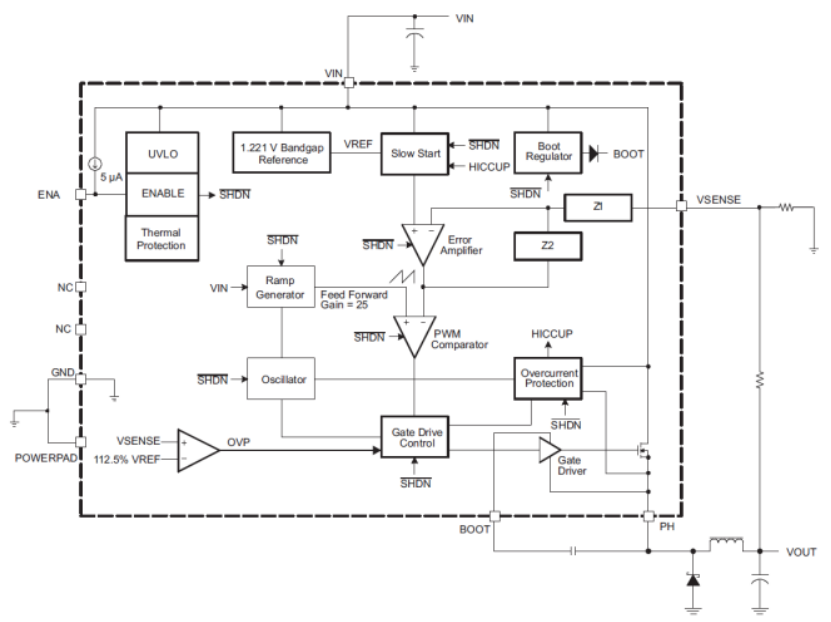

Fig. 7. Functional block diagram of TPS5450 [10].

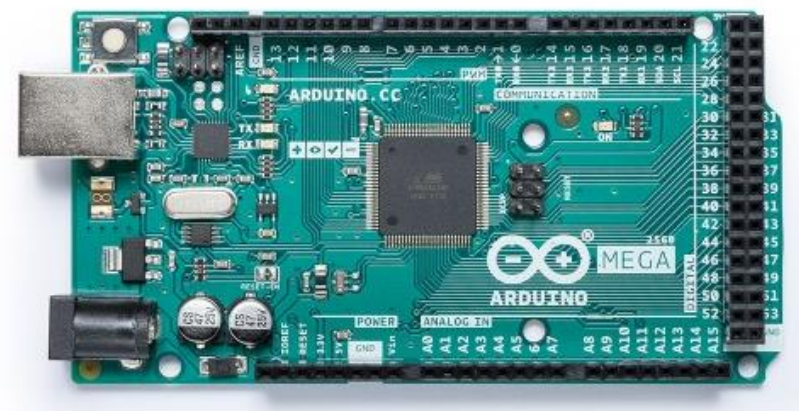

Fig. 8. Arduino mega 2560 microcontroller board [11].

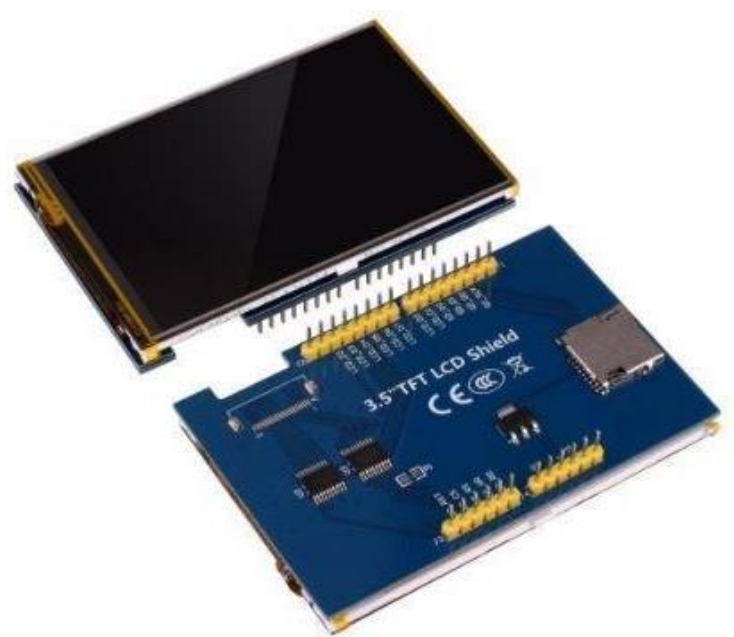

Fig. 9. 3.5-inch-480x320-TFT-LCD-Shield.

\section{Algorithm use for calculating the calories burned}

For calculating the total calories burned by the user, th user will firstly need to provide data through the provided user interface and key in the data for gender $(\mathrm{G})$, body weight $(\mathrm{W})$, height $(\mathrm{H})$ and age $(\mathrm{Y})$. Based on this information, the Basal Metabolic Rate (BMR) is calculated as follow.

- if $\mathrm{G}$ is male $\mathrm{BMR}=(10 \times \mathrm{W})+(6.25 \times \mathrm{H})-(5 \times \mathrm{Y})+5$

- if $\mathrm{G}$ is female $\operatorname{BMR}=(10 \times \mathrm{W})+(6.25 \times \mathrm{H})-(5 \times \mathrm{Y})-161$

The next step is the calculation of Metabolic Equivalent of Task (MET) based on the following Table I.

TABLE II. Relation between cycling speed and Metabolic Equivalent of Task (MET)

\begin{tabular}{|c|c|}
\hline Cycling speed (km/h) & Equivalent MET \\
\hline$<16.1$ & 4 \\
\hline $16.1<$ speed $<19.2$ & 6.8 \\
\hline $19.2<$ speed $<22.4$ & 8 \\
\hline $22.5<$ speed $<25.7$ & 10 \\
\hline
\end{tabular}

Finally, the total calories burned can be determined as follow.

Calories burned $(\mathrm{kcal})=$ BMR x $(\mathrm{MET} / 24) \mathrm{x}$ times (in hour)

For example, a 43 year old male with weight of $79 \mathrm{~kg}$, height $165 \mathrm{~cm}$ cycling at a speed of $22 \mathrm{~km} / \mathrm{h}$ for 30 minutes will burn a total $268.54 \mathrm{kcal}$ while operating the cycling charger.

\section{CYCLING CHARGER DEVELOPMENT RESULTS}

Fig. 10 shows the developed prototype of the stationary cycling charger. A used cycling trainer frame is used as the base which has a $50 \mathrm{~cm}$ diameter wheel. The DC motor is installed at the bottom side and a $2 \mathrm{~cm}$ conveyer belt relays the rotation of the wheel to the $5.5 \mathrm{~cm}$ diameter pulley attached to the motor shaft. 

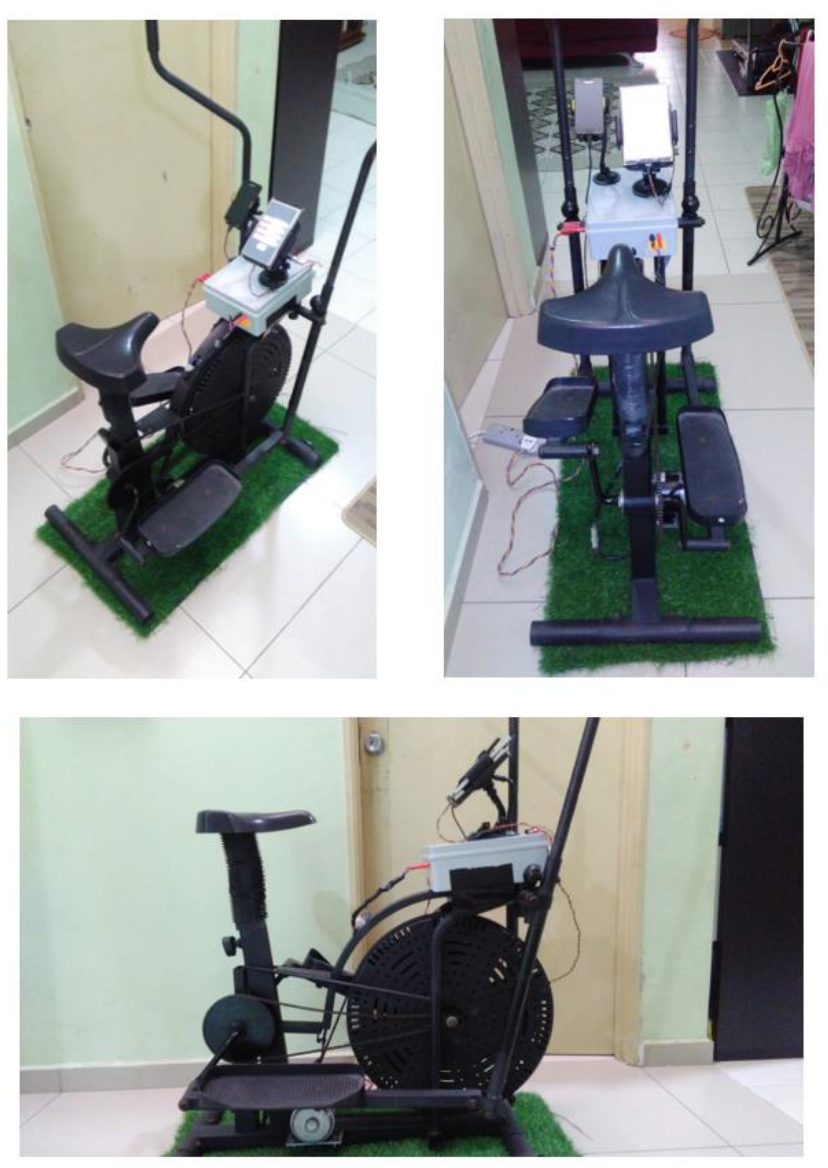

Fig. 10. The developed stationary cycling charger prototype.

Evaluation on the performance of the developed stationary cycling charger is carried out by conducting several measurements. As shown in Table II, minimum cycling speed at around 8 to $11.5 \mathrm{~km} / \mathrm{h}$ is enough to generate around 6 to $8 \mathrm{~V}$ of voltage as an input to the DC-DC converter circuit and as the speed is increased, a voltage around 13 to $15 \mathrm{~V}$ can be achieved at the speed of 18 to $23.5 \mathrm{~km} / \mathrm{h}$. This is a good range as the cycling charger can be used for quite range of user with different cycling speed ability. Minimum voltage of $5.5 \mathrm{~V}$ must be produced by the DC motor before the DC-DC converter starts to operate and charging the battery of smartphone. The screen also displays a message, telling the user if the cycling speed is too low, within the suitable range or over speeding as a safety measure as shown in Fig. 11.

As for the charging current flowing into the battery, it is found that cycling speed does not affect how fast the smartphone battery can be charged. Instead, the amount of current withdrawn by the battery is based on the battery's state of charge (SoC) condition. Based on the measurement carried out, the amount of charging current ranges between $100-400 \mathrm{~mA}$ for SoC between $30 \%-80 \%$ and drops to less than $100 \mathrm{~mA}$ when the SoC is reaching more than $80 \%$ SoC. So as a conclusion, a relaxing cycling speed between 8 to 11 $\mathrm{km} / \mathrm{h}$ is enough the charge the device.
TABLE II. Relation between cycling speed and produced voltage

\begin{tabular}{|c|c|}
\hline Cycling speed $(\mathbf{k m} / \mathbf{h})$ & $\begin{array}{c}\text { Voltage at terminal } \\
\text { of DC motor }(\mathrm{V})\end{array}$ \\
\hline $8-11.5$ & $6-8$ \\
\hline $18-23.5$ & $13-15$ \\
\hline
\end{tabular}

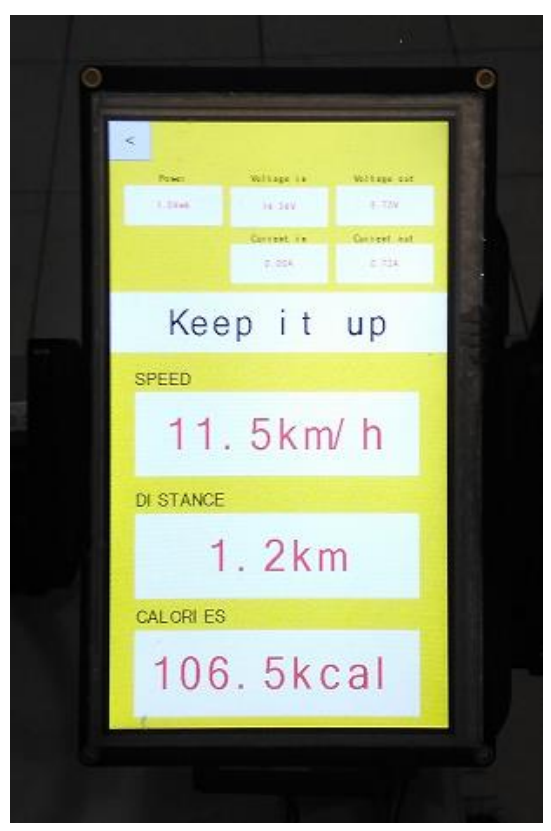

Fig. 11. User interface and information display.

\section{CONCLUSION}

This work presents the design and a development of a stationary cycling charger prototype. It details the components and devices used, as well as the algorithm for calculating the necessary information. Based on the verification on the produced prototype, it successfully operates as a charger for the smartphone device with a minimum cycling effort by the user.

\section{ACKNOWLEDGMENT}

This research project is funded by MZTURBO Energy Oil Sdn Bhd with approval from Universiti Kebangsaan Malaysia, project code: FF-2018-237. The authors also would like to acknowledge the Universiti Teknikal Malaysia Melaka for the research facilities provided in completing the prototype development.

\section{REFERENCES}

1. Online. Convergence Tech, Inc., accessed 1 August 2019, <http://www.econvergence.net/product-p/pawa-1.htm>

2. Online. Rock The Bike, accessed 1 August 2019, <https://rockthebike.com/recharge-station/>

3. Online. WeWatt, accessed 1 August 2019, < http://wewatt.com/pedal-powered-multi-device-charging-station/>.

4. Online. Star2.com, accessed 1 August 2019, <http:// www.star2.com/health/2018/08/14/fat-state-of-affairs/>. 


\section{Design and Development of Integrated Stationary Cycling Charger for Promoting Healthy Lifestyle}

5. Y. S. Hwang, C. C. Wang, F. C. Yang, and J. J. Chen, "New compact CMOS Li-Ion battery charger using charge-pump technique for portable applications," IEEE Trans. Circuits Syst. I, Reg. Papers, vol. 54, no. 4, pp. 705-712, Apr. 2007.

6. Y.-L. Ke and Y.-C. Chuang, "A novel high-efficiency battery charger with a buck zero-voltage-switching resonant converter," IEEE Trans. Energy Convers., vol. 22, no. 4, pp. 848-854, Dec. 2007.

7. S.-H. Jung, Y.-J. Woo, N.-I. Kim, and G.-H. Cho, "Analog-digital switching mixed mode low ripple high efficiency Li-Ion battery charger," in Conf. Rec. 36th IEEE IAS Annu. Meeting, Oct. 2001, pp. 2473-2477.

8. M. J. Isaacson, R. P. Hollandsworth, P. J. Giampaoli, F. A. Linkowsky, A. Salim, and V. L. Teofilo, "Advance lithium ion battery charger," in Proc. IEEE 15th Annu. Battery Conf. Appl. Advances, Jan. 2000, pp. 193-198.

9. Online. electronicsforu.com , accessed 10 August 2019, <https:// electronicsforu.com/electronics-projects/hardware-diy/bicycle-usb-char ger>.

10.Online. Texas Instrument User's Guide-TPS5450EVM-254 5-A, SWIFT $^{\mathrm{TM}}$ Regulator Evaluation Module, accessed 9 January 2019, $<$ http://www.ti.com/lit/ug/slvu211/slvu211.pdf>.

11. Online. Arduino Mega 2560, accessed 20 January 2019, $<$ https://store.arduino.cc/usa/mega-2560-r3>.

\section{AUTHORS PROFILE}

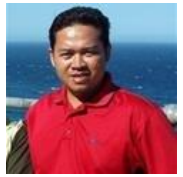

Zulhani Rasin, received his Ph.D - Electrical Engineering from The University of New South Wales, Australia in 2015. Currently a senior lecturer at the Faculty of Electrical Engineering in Universiti Teknikal Malaysia Melaka. He is actively involved in research area of power electronics and drives, particularly on $\mathrm{PV}$ inverter application and energy storage for electric vehicle application.

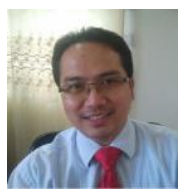

Faiz Daud, obtained his MBBS from International Islamic University Malaysia and Master in Public Health from University of Sydney, Australia in 2006 and 2013 respectively. Currently a medical lecturer in public health at Faculty of Medicine at Universiti Kebangsaan Malaysia, Malaysia. He is active in research related to healthy lifestyle promotion and student mobile learning.

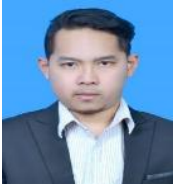

Muhammad Amruha Md Zan, obtained the B.Eng. in Electrical @ Electronics Engineering from Universiti Tenaga Nasional, Malaysia in 2002. Currently a Sales \& Technical Manager at MZ Turbo Energy Oil Sdn Bhd, he has a wide experience in the oil and gas industry, ranging from project management to testing and commissioning activities.

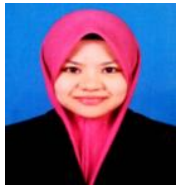

Natrah Abd Rani, received her Bachelor of Social Sciences with Honours (Social Work) and Master in Medical Social Work from Universiti Kebangsaan Malaysia in 2015 and 2018 respectively. Currently a research assistant with the Department of Public Health, Faculty of Medicine, Universiti Kebangsaan Malaysia. She is actively involved in research activities related to public and occupational health.

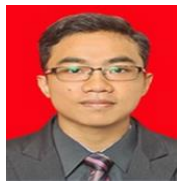

Mohd Akhmal Syafi Md Yazid, is currently in the third year of his study in Mechatronics Engineering at the Faculty of Electrical Engineering, Universiti Teknikal Malaysia Melaka. He is highly passionate in engineering innovation projects related to robotics, automation and coding solutions. He represents the faculty and won several awards in students innovation exhibition and competition at the national level. 